Open Access

\title{
Validation of the German version of the STarT-Back Tool (STarT-G): a cohort study with patients from primary care practices
}

Sven Karstens ${ }^{1 *}$, Katja Krug ${ }^{1}$, Jonathan C. Hill ${ }^{2}$, Christian Stock ${ }^{3}$, Jost Steinhaeuser ${ }^{4}$, Joachim Szecsenyi ${ }^{1}$ and Stefanie Joos ${ }^{1,5}$

\begin{abstract}
Background: Current research emphasizes the high prevalence and costs of low back pain (LBP). The STarT Back Tool was designed to support primary care decision making for treatment by helping to determine the treatment prognosis of patients with non-specific low back pain. The German version is the STarT-G. The cross-cultural translation of the tool followed a structured and widely accepted process but to date it was only partially validated with a small sample.

The aim of the study was to test the psychometric properties construct validity, discriminative ability, internal consistency and test-retest-reliability of the STarT-G and to compare them with values given for the original English version.
\end{abstract}

Methods: A consecutive cohort study with a two-week retest was conducted among patients with non-specific LBP, aged 18 to 60 years, from primary care practices. Questionnaires were collected before the first consultation, and two weeks later by post, using the following reference standards: the Roland and Morris disability questionnaire, the Tampa Scale of Kinesiophobia, the Pain Catastrophizing Scale and the Hospital Anxiety and Depression Scale.

Psychometric properties examined included the tool's discriminative abilities, whether the psychosocial subscale was one factor, internal consistency, item redundancy, test-retest reliability and floor and ceiling effects.

Results: There were 228 patients recruited with a mean age of 42.2 (SD 11.0) years, and $53 \%$ were female. The areas under the curve (AUC) for discriminative ability ranged from 0.70 (STarT-G Subscale - Pain Catastrophizing Scale; Cl95 $0.63,0.78$ ) to 0.77 (STarT-G Total - Composite reference standard, Cl95 0.60, 0.94). Factor loadings ranged from 0.49 to 0.74 . Cronbach's alpha testing the internal consistency and redundancy for the total/subscale scores were $a=0.52 / 0.55$ respectively. The STarT-G test-retest reliability Kappa values for the total/subscale scores were $0.67 / 0.68$ respectively. No floor or ceiling effects were present.

Conclusions: The STarT-G shows acceptable psychometric properties although not in exact agreement with the original English version. The items previously regarded as a psychosocial subscale may be better seen as an index of different individual psychosocial constructs. The relevance of using the tool at the point of consultation should be further examined.

Keywords: Low back pain, Questionnaire, Psychosocial factors, Therapy prognosis

\footnotetext{
* Correspondence: sven.karstens@med.uni-heidelberg.de

${ }^{1}$ Department of General Practice and Health Services Research, University

Hospital Heidelberg, Heidelberg, Germany

Full list of author information is available at the end of the article
}

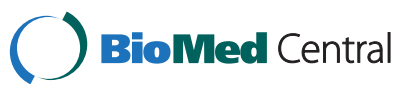

(c) 2015 Karstens et al. Open Access This article is distributed under the terms of the Creative Commons Attribution 4.0 International License (http://creativecommons.org/licenses/by/4.0/), which permits unrestricted use, distribution, and reproduction in any medium, provided you give appropriate credit to the original author(s) and the source, provide a link to the Creative Commons license, and indicate if changes were made. The Creative Commons Public Domain Dedication waiver (http://creativecommons.org/publicdomain/zero/1.0/) applies to the data made available in this article, unless otherwise stated. 


\section{Background}

Low back pain (LBP) ranks the highest of all conditions in terms of years lived with disability, both in Western Europe and Worldwide [1]. This has enormous economic consequences on health care expenditure and loss of work productivity [2, 3]. Complex biopsychosocial mechanisms are known to be involved in the development of chronic disabling LBP and as a result the variation in treatment prognosis for individual patients is considerable [4]. This means, that although a number of effective treatments are available, selecting appropriate treatment for individual patients remains a substantial clinical challenge for primary care where most patients are managed [5-7].

An internationally agreed research priority is to test whether the effectiveness of treatment results might be improved by early identification of patient-subgroups that are most at risk for developing chronic disabling pain [8]. Several different approaches for subgrouping patients with low back pain have been developed [9]. One with feasibility and demonstrated clinical and cost effectiveness is the STarT Back stratified care approach involving the use of the Keele STarT Back Tool (SBT), which has specifically been designed for primary care to fast-track patients to appropriate treatment based on prognostic information. The tool assists clinicians in determining an individual's likely prognosis and consists of nine items, with the first four relating to biomedical factors and the last five identifying modifiable psychosocial risk factors [10]. Patients are then allocated to one of three prognostic groups (low, medium and high risk) using established scoring cut-offs which each have different matched treatment recommendations [11, 12]. Patients at low risk receive support to self-manage and are deliberately not over treated or investigated. Patients at medium risk are provided with evidence-based physiotherapy treatment such as exercise and manual therapy, and patients at high risk receive psychologically informed physiotherapy, which integrates physical and psychological approaches, aiming at reducing obstacles to recovery such as unhelpful beliefs and illness behaviors. Following promising research findings the approach is gradually being implemented into routine practice in the UK [13] and some initial research has reported promising findings that implementing this approach in Germany might be possible [14].

The SBT was originally developed in the UK and has been translated into over 25 languages with 15 articles validating the psychometric properties of different versions [15]. The German version (STarT-G) was developed following a structured and widely accepted cross-cultural translation process [16]. In addition, some initial psychometric testing on a small cohort in Switzerland has been reported [17]. However, as the sample size was small and only a limited number of measurement properties were tested, we aimed to conduct a larger scale German validation study.

The specific objectives of our study were to test the STarT-G's construct validity, discriminative ability, internal consistency and test-retest-reliability and to compare findings with the values given for the original English version.

\section{Methods}

A cohort study with a two-week retest has been conducted. Patients with LBP were recruited from primary care (general practices and orthopaedic practices both with free access to care). The first questionnaire (t0) took place within the practice before consultation, and the second questionnaire was sent by post (t1) 10 days later. Patients who did not respond to the postal questionnaire were contacted by telephone.

Nine general practices and two orthopaedic practices participated with eight being single-handed, and three having more than one physician. Before patients were recruited, each practice received training from the studyteam involving:

- An introduction to the STarT Back Tool,

- The informed consent procedure,

- Information about the data collection procedure,

- Information on transferring collected data from the practice to the study center,

- Information about study reimbursement.

Inclusion criteria were patients with non-specific LBP, aged 18 to 60 years. The diagnosis of low back pain was defined as being specific, if a patient had a cauda equina syndrome, an inflammatory disorder such as ankylosing spondylitis, or had a suspected serious pathology such as a tumor or vertebral fracture. No restrictions were placed on the duration of a patient's back pain symptoms. Patients were excluded, if they had consulted the physician within the last twelve weeks, had undergone spinal surgery within the last six months, or if they were unable to complete the study questionnaires due to poor German language skills. Anonymized information on eligible patients' age and gender was obtained regardless of study participation ("consent list").

The retest-material was sent to patients 10 days after the baseline assessment from the study-center. This duration was set to counter memory effects. Since it was likely that the health status would change at least for a part of the patients, an additional question on the subjective estimation of whether their complaints had changed over this period, was added [18]. Patients who did not respond to the postal questionnaire within two weeks were telephoned and reminded to send the questionnaire, or alternatively asked 
to answer a limited set of questions. The retest-process was managed by a specifically constructed database to ensure the maintenance of the predefined time intervals.

Ethical approval was granted by the Ethics Committee of the University of Heidelberg (registration ID: S-414/ 2013). All patients gave their written informed consent for participation before entering the study in the participating practice.

\section{Instruments}

In addition to the STarT-G, several validated German versions of reference standard instruments were included in the study questionnaire. Disability was operationalized using the Roland and Morris disability questionnaire (RMDQ) [19], fear avoidance beliefs were operationalized with the 17-item-version of the Tampa Scale of Kinesiophobia (TSK) [20], catastrophizing with the Pain Catastrophizing Scale (PCS) [21] and depression with the Hospital Anxiety and Depression Scale (HADS) [22]. Pain intensity was measured using the mean of three eleven-point box-scales for least, average (over the previous two weeks), and current pain [23, 24]. Standardized questions were used for documentation of the patients' age, gender and body-mass-index (BMI), information on type of employment, days off work due to LBP and the duration of the back pain episode $[25,26]$.

The wording of two questions of the STarT-G were slightly modified lowering their item-difficulty. Because of the very high difficulty of item 5 and 8 found within the first study conducted in Switzerland, a rewording was undertaken in agreement with the developers of the SBT [17]. The STarT-G can be obtained from the authors via email.

The definitions for reference standard cases were catastrophizing (PCS score $\geq 20$ ), fear (TSK score $\geq 41$ ), depression (HADS-D score $\geq 8$ ) and disability (RMDQ score $\geq 7$ ) $[11,22]$. Furthermore, a composite reference standard (CRS; 'distress') was determined, defined by individuals that were a 'case' simultaneously in the three psychosocial reference standard questionnaires: TSK, PCS and HADS depression. Following pretesting with selected LBP patients, the estimated time for the entire study questionnaire completion was 15 minutes.

\section{Statistical analyses}

Descriptive statistics were calculated to characterize the study population. The baseline characteristics of study participants were described to allow interpretability of the study sample, together with data about drop-outs, missing data and recruitment rate.

Discriminative ability was assessed by computing receiver operating characteristic curves with areas under the curves (AUC) and $95 \%$ confidence interval (CI). Consistent with the original validation of the English
SBT, this was done for disability, catastrophising and distress [27]. Adjectives that can be used to describe AUCvalues have been proposed by Hosmer and Lemeshow with an $\mathrm{AUC}=0.5$ suggesting 'no discrimination', 0.7 to $<0.8$ considered 'acceptable discrimination', 0.8 to 0.9 considered 'excellent discrimination' and $>0.9$ considered 'outstanding discrimination' [28]. To determine if a patient was a 'case' on reference standard instruments, the individual's scores were compared to cut-off values given under the subheading Instruments (see "definitions for reference standard cases"). Since the CI determined by Hill et al. did not fall short of AUC $=0.7$ [10], equivalence was expected if the lower CI did not fall short of the same cut-off.

In addition to the AUC, helping to interpret the relations between the instruments, Spearmans correlation coefficients were calculated for the STarT-G total and subscale scores for the RMDQ, TSK, PCS and HADS depression scores in order to be consistent to the approach of the original SBT authors.

To test if the psychosocial subscale could be regarded as one factor, a principal components analysis was undertaken. In general, at least four items should exceed 0.6 [29]. For the original version of the SBT, factor loadings between 0.6 and 0.8 were calculated; therefore equivalence was expected if the STarT-G values would exceed 0.6 for these five psychosocial items.

To determine internal consistency and item redundancy for the psychosocial subscale, the Cronbach's alpha was calculated (poor internal consistency was defined as $\alpha<0.70$, item redundancy was defined as $\alpha>$ 0.90) [30]. Since the original SBT validation study reported values ranging between 0.7 and 0.9 , equivalence was expected if Alpha was within this same range.

To investigate the test-retest reliability, Cohen's quadratic weighted Kappa was calculated for the overall and subscale scores [31]. Since we had to expect that the health status would change between $\mathrm{t} 0$ and $\mathrm{t} 1$ at least for some patients, and that the STarT-G is responsive, testretest calculations were limited to patients who selfreported their health problems to be unchanged over the two time-points [32]. A range between Kappa 0.6 and 0.8 was defined as good agreement. The values of 0.79 for the SBT total score and 0.76 for the subscale score calculated by Hill et al. lay within this range [10]. Therefore, equivalence was expected with a Kappa score of $>0.6$. A sensitivity analysis was planned excluding retest data gathered via telephone.

Floor and ceiling effects were defined as present if more than $15 \%$ of the responders achieved the lowest or highest possible STarT-G total score [33].

All statistical tests were two-sided and a significance level of alpha $=5 \%$ was used. Analysis was generally performed using SPSS version 20.0. Principal component analyses and Kappa calculations were performed using 
the $\mathrm{R}$ language and environment for statistical computing, version 3.1.1 [34].

\section{Sample size}

Principal component analysis was expected to be the procedure with the need for the largest sample size. For calculation, the formula given by Bortz and Schuster was considered [29]. With a minimally expected factor loading of 0.4 and a stability of 0.9 , a sample size of $n=180$ resulted. This led to the conclusion that using the same sample size of 200 as defined for the original SBT validation study would be sufficient [10].

\section{Results}

Consent for participation was given by 228 patients (90.1\%), with 25 declining (9.9\%). Consenters and nonconsenters did not differ statistically significant by age or gender. The mean age of study participants was 42.2 (SD 11.0 ) years, and $53 \%$ were female (Table 1 ). During the previous twelve weeks before t0, 31 patients $(13.6 \%)$ reported having taken some sick leave, with a mean of 13.3 (SD 21.2) days off work. The t1 questionnaire was returned by 181 patients (79.4\%), with an additional 4 patients answering questions on the telephone $(1.8 \%$; $81.1 \%$ in total). Non-respondents at t 1 were significantly younger and more often male. The mean time difference between the completion of the $\mathrm{t} 0$ and the $\mathrm{t} 1$ questionnaire was 21.1 (SD 13.3) days.

Due to missing answers (9 questionnaires) or invalid answers (12 questionnaires, both (missing and invalid answers) 2 questionnaires), it was not possible to calculate the STarT-G total score for 23 patients and subscale score for 19 patients.

The AUCs for STarT-G's ability to discriminate reference standard cases ranged from 0.70 to 0.77 , indicating acceptable discrimination (Table 2 and Fig. 1a-d). Since the lower CIs all fell short of 0.7, the STarT-G's discriminative abilities were not equivalent to the original SBT version according to our pre-defined criteria.

All correlation coefficients were significant (Table 3), with values ranging from 0.28 to 0.46 .

Factor loadings ranged from 0.49 to 0.74 with items 5 and 6 falling short of the predefined threshold $(<0.6)$ for equivalence with the original SBT (Table 4).

With $\alpha=0.55$ for the subscale score, and $\alpha=0.52$ for the total score, internal consistency was poor. Since Cronbach's alpha fell short of the predefined threshold for equivalence, equivalence to the original version of the SBT was not reached.

Data from 30 patients, who self-rated their health problems as unchanged, was included in the analysis for the test-retest-reliability. With Kappa $=0.67 / 0.68$ (95\% CI 0.46-0.81/0.48-0.84) for the total score and the subscale score respectively, agreement was good
Table 1 Characteristics of the study population, $n=228$

\begin{tabular}{|c|c|c|}
\hline Mean age in years $(S D) n$ & $42.2(11.0)$ & 228 \\
\hline Gender female \%, n & 53 & 120 \\
\hline Mean Body-Mass-Index in $\mathrm{kg} / \mathrm{m}^{2}$ (SD) $\mathrm{n}$ & $26.7(5.0)$ & 225 \\
\hline \multicolumn{3}{|l|}{ Employment \%, n } \\
\hline Not working & 4.9 & 11 \\
\hline Working $\geq 35$ hours & 62.9 & 141 \\
\hline Working 15 to 34 hours & 25.0 & 56 \\
\hline Working $<15$ hours & 2.7 & 6 \\
\hline Parental or other leave & 3.1 & 7 \\
\hline Trainee/retrainee/prentice & 1.3 & 3 \\
\hline Total & 100 & 224 \\
\hline Mean Pain intensity (SD) $n$ & $4.3(1.7)$ & 225 \\
\hline Mean Disability (RMDQ; SD) n & $9.9(5.2)$ & 204 \\
\hline \multicolumn{3}{|l|}{ Duration of current episode $\%, n$} \\
\hline$<6$ weeks & 60.3 & 135 \\
\hline 6 to 12 weeks & 8.9 & 20 \\
\hline$>12$ weeks to 0.5 year & 5.8 & 13 \\
\hline$>0.5$ year & 25.0 & 56 \\
\hline Total & 100 & 224 \\
\hline Sick leave within the previous 12 weeks $\%, n^{a}$ & 13.6 & 31 \\
\hline Mean HADS-D (depression; SD) n & $4.7(3.5)$ & 224 \\
\hline Mean PCS (SD) n & $16.7(10.5)$ & 227 \\
\hline Mean TSK (SD) n & $32.9(6.7)$ & 228 \\
\hline Mean STarT-G total (SD) n & $3.9(2.0)$ & 205 \\
\hline Mean STarT-G subscale (SD) n & $2.0(1.4)$ & 209 \\
\hline \multicolumn{3}{|l|}{ STarT-G risk group \%, $\mathrm{n}$} \\
\hline Low risk & 38.6 & 80 \\
\hline Medium risk & 43.5 & 90 \\
\hline High risk & 17.9 & 37 \\
\hline Total & 100 & 207 \\
\hline
\end{tabular}

HADS-D Hospital Anxiety and Depression Scale (Depression), PCS Pain Catastrophizing Scale, RMDQ Roland Morris Disability Questionnaire, TSK Tampa Scale of Kinesiophobia

a Medically certified sick within twelve weeks before to

Table 2 Areas under the curve (AUC)

\begin{tabular}{lllll}
\hline & AUC & SE & $95 \% \mathrm{Cl}$ & \\
\hline STarT-G Total - RMDQ & 0.76 & 0.04 & 0.68 & 0.83 \\
STarT-G Sub - PCS & 0.70 & 0.04 & 0.63 & 0.78 \\
STarT-G Sub - HADS-D & 0.71 & 0.05 & 0.61 & 0.81 \\
STarT-G Sub - CRS & 0.77 & 0.09 & 0.60 & 0.94 \\
\hline
\end{tabular}

HADS-D: Hospital Anxiety and Depression Scale (Depression), PCS: Pain Catastrophizing Scale, RMDQ: Roland Morris Disability Questionnaire, CRS: composite reference standard 


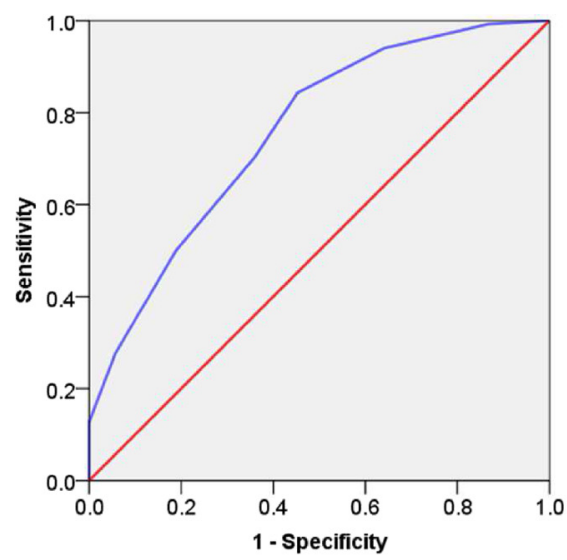

a) RMDQ

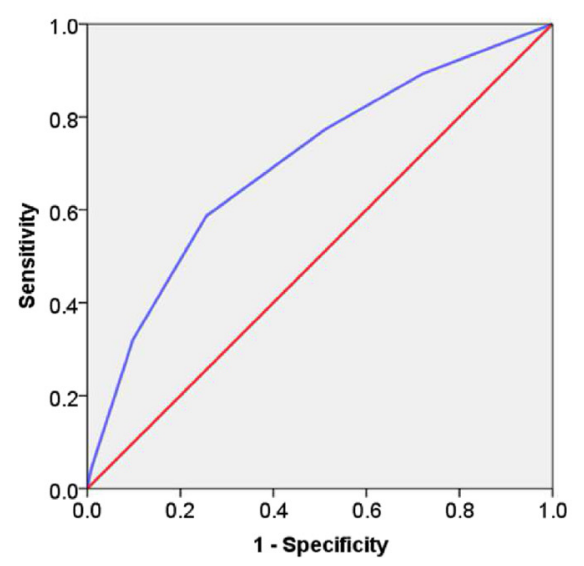

c) PCS

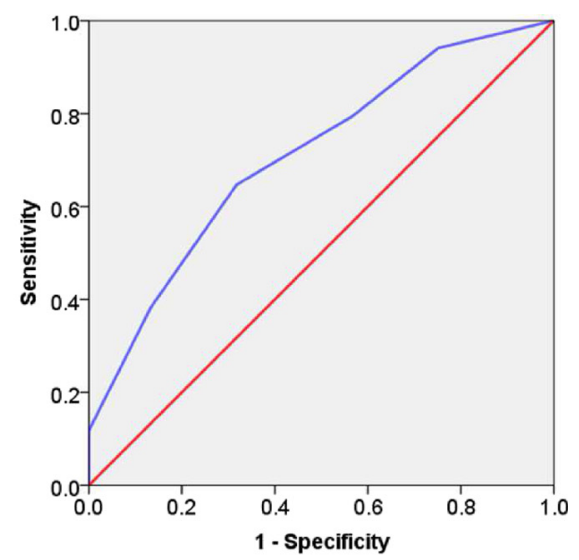

b) HADS-D

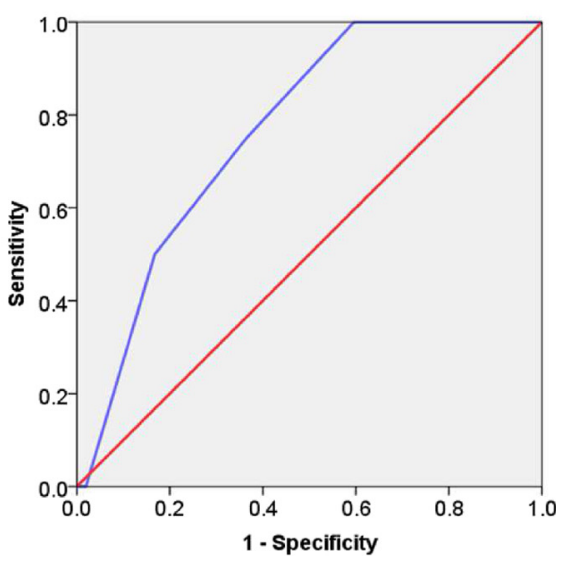

d) CRS

Fig. 1 a-d Receiver operating characteristic curves. HADS-D: Hospital Anxiety and Depression Scale (Depression), PCS: Pain Catastrophizing Scale, RMDQ: Roland Morris Disability Questionnaire, CRS: composite reference standard

and equivalent to the original version of the SBT. An additional calculation for the risk-groups resulted in Kappa $=0.28$ (95\% CI 0.23-0.55). The planned sensitivity analysis excluding retest data gathered via telephone was not possible as none of the four patients responding via telephone rated their health problems as unchanged.

Table 3 Spearman correlation coefficients, for each instrument for STarT-G-total score and subscale score

\begin{tabular}{llllcll}
\hline & Total & $95 \% \mathrm{Cl}$ & & Subscale & $95 \% \mathrm{Cl}$ & \\
\hline RMDQ & $0.46^{\mathrm{a}}$ & 0.32 & 0.58 & $0.39^{\mathrm{a}}$ & 0.25 & 0.52 \\
PCS & $0.30^{\mathrm{a}}$ & 0.17 & 0.43 & $0.40^{\mathrm{a}}$ & 0.27 & 0.52 \\
TSK & $0.28^{\mathrm{a}}$ & 0.14 & 0.41 & $0.30^{\mathrm{a}}$ & 0.17 & 0.42 \\
HADS-D & $0.32^{\mathrm{a}}$ & 0.19 & 0.43 & $0.34^{\mathrm{a}}$ & 0.21 & 0.46
\end{tabular}

HADS-D Hospital Anxiety and Depression Scale (Depression), PCS Pain Catastrophizing Scale, RMDQ Roland Morris Disability Questionnaire, TSK Tampa Scale of Kinesiophobia

${ }^{a}$ significant (two-tailed, level $=0.01$ )
With equivalence to the original SBT version, no floor or ceiling effects were found for the STarT-G $(3.9 \%(n=8)$ patients with 0 points; no patients with 9 points).

\section{Discussion}

The STarT-G did not show identical psychometric properties to the original English version although our riskgroup distribution was comparable to the original SBT validation study. The measurement properties of the STarT-G showed good test-retest reliability for the total score and the subscale score, acceptable discriminative

Table 4 Correlation of the variables with the component

\begin{tabular}{llll}
\hline STarT-G & $P C 1$ & $h^{2}$ & $\mathrm{u}^{2}$ \\
\hline Item 5 & 0.49 & 0.24 & 0.76 \\
Item 6 & 0.51 & 0.26 & 0.74 \\
Item 7 & 0.74 & 0.55 & 0.45 \\
Item 8 & 0.63 & 0.39 & 0.61 \\
Item 9 & 0.65 & 0.42 & 0.58 \\
\hline
\end{tabular}


ability and no floor or ceiling effects. Correlations with the total score reference standards for disability, and subscale score for catastrophising were acceptable. The correlations with the subscale score reference standards for kinesiophobia and depression and the test-retest reliability for risk-group allocation among patients who reported stable symptoms were weak. The psychosocial subscale of the STarT-G (items five to nine) should not be regarded as one distress factor, as the internal consistency of the corresponding items was poor.

According to pre-defined criteria the properties of the STarT-G differ in a number of respects from those of the original SBT. It is common that measurement tools perform less well in further validation studies in comparison to the developmental study [35]. In addition, we were not able to identify commonly accepted methods for the comparison of the measurement properties of the two instrument versions. A method we found to compare the tools' discriminative abilities has been subject to criticism [27]. Therefore we used a pragmatic approach, which may have led to an over-estimation of the differences between both instruments. Nevertheless, international comparisons between different cohorts using the STarT-G and the SBT should be undertaken cautiously.

Our decision to exclude patients who had consulted their physician within the previous twelve weeks meant that in comparison to the original study sample and other SBT related studies we had greater numbers of patients with a short duration back pain symptoms [36-41]. As a result, some of the differences in the STarT-G's psychometric properties may be due to the differences between the populations studied. The results of Beneciuk et al. support this perspective, as they specifically analyzed the relevance of the timing of the SBT and found that especially in acute high-risk patients, tool scores often change within a few weeks. They therefore suggest further research examining the potential of repeated measures in helping to improve the accuracy of prognostic assessment in this subgroup [42].

In the original SBT validation study the psychosocial subscale was confirmed to be one overall 'distress' factor. However, this finding was not replicated in our STarT-G validation study and in fact is consistent with a Danish validation study which described the SBT as 'a multidimensional questionnaire consisting of one or two screening questions for each of eight underlying constructs' and therefore recommended a stronger itembased approach for validation [36]. Whilst this finding is of interest, it might not have a large impact on the STarTG's ability of stratify patients in primary care.

In relation to relevant reference standards our results identified that the psychosocial subscale of the STarT-G and the TSK (for fear avoidance beliefs) had the lowest correlation. The reason for this issue is unclear although it is noted that in an updated version of the TSK, the instrument includes six items less than the version we used. This reduction was triggered by problems described for the TSK factor-structure in the international literature [20]. Therefore, in future studies it might be useful to include other instruments for fear avoidance or other versions of the TSK. For the study described in this manuscript we slightly modified the wording of two previous STarT-G items, number five about fear of movement (kinesiophobia) and number eight about low mood (depression). It is possible that the lower correlation between the subscale score and reference standards for kinesiophobia and depression was due to this re-wording, however this would seem unlikely, especially since the new formulation of item five resulted in a higher conformity to the original TSK-item which was used to develop the STarT-Tool [8].

Missing answers leading to invalid STarT-G scores although anticipated - were only a small proportion $(<4 \%)$, with more than half of these due to patients giving ambiguous responses, e.g. ticks in between the 'Agree'/'Disagree' boxes. For the Chinese version of the SBT missing data was also an issue although to a lesser extent [41]. Our results suggest that an estimated tenth of all patients return incomplete STarT-scores making it impossible to calculate their risk subgroup without further enquiry. This occurred despite specific attention from the study team to ensure appropriate instructions were in bold, such as 'answer each question if possible and try not to spend too long over your answers but pick the answer that first comes to mind'. In clinical practice therapists clearly have the opportunity to ask patients if this occurs. However, we recommend that a clear definition and evaluation method of missing-data for the SBT is considered in order that more responses with missing data are able to be used.

In Germany, it is likely that physiotherapists and primary care physicians will be the primary users of the STarT-G [13]. This study, provides them with clear information on the instrument's measurement properties. The stratification tool is designed to assist clinicians in their decision-making process and not to replace their decision-making. In addition, the STarT Back approach upskills physiotherapists, through a training course, to address the complex needs of high-risk patients through the delivery of 'psychologically informed physiotherapy'. Evidence suggests that trained physiotherapists are effective in managing around $85 \%$ of this high-risk complex patient subgroup [43-46]. Nevertheless, the systematic review by Kenny et al. concludes that, from an international perspective, the SBT should still be considered as being in a developmental stage and should therefore be 
used with caution in practice [15]. Our results indicate that this also applies for the German version.

Strengths of this study were that the design was clearly planned a priori and rigorously applied. Experiences from a first small validation pilot in Switzerland reinforced the selection of primary care practices as the appropriate setting for this study since the clinical context has a strong influence on the answers patients provide. Moreover, in contrast to the Swiss study, pre firstcontact consultation as the first time-point for administrating the STarT-G was chosen to include patients who had not yet received any treatment $[17,47]$. In addition, a half-year mailing is currently being carried out, to determine the predictive ability of the STarT-G. Other strengths include achieving an appropriate sample size and ensuring non-responders were contacted by telephone to ensure a high follow-up rate. In respect to interpreting the test-retest-reliability findings some caution is appropriate, since the Kappa-value calculations were limited to a relatively small subsample of patients who self-reported their health problems as being unchanged for the observed study period.

The potential for cost savings and better costeffectiveness of the STarT-approach has been demonstrated by Hill et al. in a large randomized controlled trial [11] and is also supported by the results from a prospective population-based sequential comparison observing the implementation of the STarT-Back-Approach in routine health care [13]. Nevertheless, results have yet to be replicated in other countries. Foster et al. propose that randomized trials are the preferred optimal design for this [9]. Correspondingly, the next step should be a feasibility pilot to examine the approach in Germany and provide information to help develop a clear implementation strategy. We have therefore conducted a related qualitative study with GPs and physiotherapists to compliment this research [14].

\section{Conclusion}

The STarT-G shows overall acceptable psychometric properties, although some differences with the original English version were identified. These included the items previously regarded as a psychosocial subscale being found to be more than one construct, and so we recommend this subscale is better understood to be a collection of individual psychosocial items. Further research utilizing the STarT-G should consider our findings and pay attention to establishing methods to deal with missing values.

\section{Abbreviations}

AUC: Area under the curve; BMI: Body-mass-index; CRS: Composite reference standard; HADS-D: Hospital anxiety and depression scale (depression); LBP: Low back pain; PCS: Pain catastrophizing scale; RMDQ: Roland and Morris disability questionnaire; SBT: STarT back tool; STarT: Subgroups for targeted treatment; STarT-G: German version of the STarT Back Tool; TSK: Tampa scale of kinesiophobia.

\section{Competing interests}

The authors have declared that no competing interests exist.

\section{Authors' contributions}

Conceived and designed the study: SK KK JSt JH CS JSz SJ. Performed the study: SK KK JSt SJ. Analyzed the data: SK KK JH CS SJ. Wrote the paper: SK $J$ H SJ KK JSz JSt CS. All authors read and approved the final manuscript.

\section{Acknowledgements}

The authors thank the research assistants Selina Böhm and Julia Dreiling for conductance of telephone interviews and administrative tasks, Daniel Zeugfang for data input and our colleague Mariell Hoffmann for conductance of telephone interviews and administrative tasks.

The study was funded by the young scientists programme of the German network 'Health Services Research Baden-Württemberg' of the Ministry of Science, Research and Arts in collaboration with the Ministry of Employment and Social Order, Family, Women and Senior Citizens, Baden-Württemberg. We acknowledge financial support by Deutsche Forschungsgemeinschaft and Ruprecht-Karls-Universität Heidelberg within the funding programme Open Access Publishing.

\section{Author details}

'Department of General Practice and Health Services Research, University Hospital Heidelberg, Heidelberg, Germany. ${ }^{2}$ Institute of Primary Care and Health Sciences, Keele University, Keele/Stoke-on-Trent, United Kingdom. ${ }^{3}$ Institute of Medical Biometry and Informatics, University of Heidelberg, Heidelberg, Germany. ${ }^{4}$ Institute of Family Medicine, University Hospital Schleswig-Holstein Campus Luebeck, Luebeck, Germany. ${ }^{5}$ Institute for General Practice and Interprofessional Care, University Hospital Tuebingen, Tuebingen, Germany.

Received: 29 July 2015 Accepted: 5 November 2015

Published online: 11 November 2015

\section{References}

1. Hoy D, March L, Brooks P, Blyth F, Woolf A, Bain C, et al. The global burden of low back pain: estimates from the Global Burden of Disease 2010 study. Ann Rheum Dis. 2014;73(6):968-74. doi:10.1136/annrheumdis-2013-204428.

2. Mafi JN, McCarthy EP, Davis RB, Landon BE. Worsening trends in the management and treatment of back pain. JAMA Intern Med. 2013;173(17):1573-81. doi:10.1001/jamainternmed.2013.8992.

3. Wenig CM, Schmidt CO, Kohlmann T, Schweikert B. Costs of back pain in Germany. Eur J Pain. 2009;13(3):280-6. doi:10.1016/j.ejpain.2008.04.005.

4. Gurung T, Ellard DR, Mistry D, Patel S, Underwood M. Identifying potential moderators for response to treatment in low back pain: A systematic review. Physiotherapy. 2015. doi:10.1016/j.physio.2015.01.006.

5. Balague F, Mannion AF, Pellise F, Cedraschi C. Non-specific low back pain. Lancet. 2012;379(9814):482-91. doi:10.1016/s0140-6736(11)60610-7.

6. Karstens S, Hermann K, Frobose I, Weiler SW. Predictors for half-year outcome of impairment in daily life for back pain patients referred for physiotherapy: a prospective observational study. PLoS One. 2013;8(4):e61587. doi:10.1371/journal.pone.0061587.

7. Koes BW, van Tulder M, Lin C-WC, Macedo LG, McAuley J, Maher C. An updated overview of clinical guidelines for the management of non-specific low back pain in primary care. Eur Spine J. 2010;19(12):2075-94. doi:10.1007/ s00586-010-1502-y.

8. Foster NE, Dziedzic KS, van der Windt DA, Fritz JM, Hay EM. Research priorities for non-pharmacological therapies for common musculoskeletal problems: nationally and internationally agreed recommendations. BMC Musculoskelet Disord. 2009;10:3. doi:10.1186/1471-2474-10-3.

9. Foster NE, Hill JC, O'Sullivan P, Hancock M. Stratified models of care. Best Pract Res Clin Rheumatol. 2013;27(5):649-61. doi:10.1016/j.berh.2013.10.005.

10. Hill JC, Dunn KM, Lewis M, Mullis R, Main CJ, Foster NE, et al. A primary care back pain screening tool: identifying patient subgroups for initial treatment. Arthritis Rheum. 2008;59(5):632-41. doi:10.1002/art.23563.

11. Hill JC, Whitehurst DG, Lewis M, Bryan S, Dunn KM, Foster NE, et al. Comparison of stratified primary care management for low back pain with current best practice (STarT Back): a randomised controlled trial. Lancet. 2011;378(9802):1560-71. doi:10.1016/S0140-6736(11)60937-9. 
12. Kongsted A, Johannesen E, Leboeuf-Yde C. Feasibility of the STarT back screening tool in chiropractic clinics: a cross-sectional study of patients with low back pain. Chiropr Man Therap. 2011;19:10. doi:10.1186/2045-709X-19-10.

13. Foster NE, Mullis R, Hill JC, Lewis M, Whitehurst DG, Doyle C, et al. Effect of stratified care for low back pain in family practice (IMPaCT Back): a prospective population-based sequential comparison. Ann Fam Med. 2014;12(2):102-11. doi:10.1370/afm.1625.

14. Karstens S, Joos S, Hill JC, Szecsenyi J, Steinhaeuser J. Implementing a targeted treatment approach for low back pain in primary care in Germany. Physiotherapy. 2015;101(Supplement 1):e724-5. http://dx.doi.org/10.1016/ j.physio.2015.03.3582.

15. Kenny D, Ball J, Bloxham C, Cashmore G, Dick F, Kannan P et al. An Evaluation of the Psychometric Properties of the STarT Back Screening Tool - a Systematic Review. Physiotherapy. 2015;101(S1).

16. Beaton D, Bombardier C, Guillemin F, Ferraz MB. Recommendations for the Cross-Cultural Adaptation of the DASH \& QuickDASH Outcome Measures. Institute for Work \& Health. 2007. http://www.dash.iwh.on.ca/system/files/XCulturalAdaptation-2007.pdf. Accessed 05.03.2013.

17. Aebischer B, Hill JC, Hilfiker R, Karstens S. German Translation and CrossCultural Adaptation of the STarT Back Screening Tool. PLoS ONE. 2015;10(7):e0132068. doi:10.1371/journal.pone.0132068.

18. Schulte E, Berghöfer A, Hermann K. Analyse der Versorgungswege von Patienten/innen mit primär therapieresistenten subakuten und chronischen Schmerzen: Schlussbericht; Förderzeitraum: Juli 2003 - Januar 2006. Berlin: Charité Universitätsmedizin; 2006.

19. Exner V, Keel P. Erfassung der Behinderung bei Patienten mit chronischen Ruckenschmerzen Validierung einer deutschen Version des "Roland \& Morris disability questionnaire" sowie verschiedener numerischer Ratingskalen. Schmerz. 2000;14(6):392-400. doi:10.1007/s004820000010.

20. Rusu AC, Kreddig N, Hallner D, Hulsebusch J, Hasenbring Ml. Fear of movement/(Re)injury in low back pain: confirmatory validation of a German version of the Tampa Scale for Kinesiophobia. BMC Musculoskelet Disord. 2014;15:280. doi:10.1186/1471-2474-15-280.

21. Meyer K, Sprott H, Mannion AF. Cross-cultural adaptation, reliability, and validity of the German version of the Pain Catastrophizing Scale. J Psychosom Res. 2008;64(5):469-78. doi:10.1016/j.jpsychores.2007.12.004.

22. Petermann F. Hospital Anxiety and Depression Scale, Deutsche Version (HADS-D). Z Psychiatr Psychol Psychother. 2011;59(3):251-3. doi:10.1024/ 1661-4747/a000077.

23. Jensen MP, Turner LR, Turner JA, Romano JM. The use of multiple-item scales for pain intensity measurement in chronic pain patients. PAIN 1996;67(1):35-40. http://dx.doi.org/10.1016/0304-3959(96)03078-3.

24. Sim J, Waterfield J. Validity, reliability an responsiveness in the assessment of pain. Physiother Theory Pract. 1997;13:23-37.

25. AEM. Arbeitsgruppe "Epidemiologische Methoden" in der Deutschen Arbeitsgemeinschaft Epidemiologie, der Gesellschaft für Medizinische Informatik, Biometrie und Epidemiologie und der Deutschen Gesellschaft für Sozialmedizin und Prävention: Messung und Quantifizierung soziographischer Merkmale in epidemiologischen Studien. o.O. 1997. http://www. gesundheitsforschung-bmbf.de/_media/ Empfehlungen_Epidemiologische_Studien.pdf. Accessed 2013 Mar 22.

26. Tuomi K, Ilmarinen J, Jahkola A, Katajarinne L, Tulkki A. Arbeistbewältigungsindex - Work Ability Index; Schriftenreihe der Bundesanstalt für Arbeitsschutz und Arbeitsmedizin: Übersetzung, Ü 14. Bremerhaven: Wirtschaftsverlag NW; Verlag für neue Wissenschaften $\mathrm{GmbH} ; 2001$.

27. Hanley JA, McNeil BJ. The meaning and use of the area under a receiver operating characteristic (ROC) curve. Radiology. 1982;143(1):29-36.

28. Hosmer DW, Lemeshow S. Applied logistic regression. 2. ed. Wiley series in probability and statistics. New York: Wiley; 2000.

29. Bortz J, Schuster C. Faktorenanalyse. In: Bortz J, Schuster C, editors. Statistik für Human- und Sozialwissenschaftler. Springer-Lehrbuch. Berlin, Heidelberg: Springer 2010. p. 385-433.

30. Streiner DL, Norman GR. Health measurement scales: a practical guide to their development and use. Oxford medical publications. Oxford: Oxford University Press; 2003.

31. Altman DG. Practical statistics for medical research. London: Chapman and Hall; 1991.

32. Wideman $\mathrm{TH}$, Hill JC, Main CJ, Lewis M, Sullivan MJ, Hay EM. Comparing the responsiveness of a brief, multidimensional risk screening tool for back pain to its unidimensional reference standards: the whole is greater than the sum of its parts. Pain. 2012;153(11):2182-91. doi:10.1016/j.pain.2012.06.010.
33. Terwee CB, Bot SD, de Boer MR, van der Windt DA, Knol DL, Dekker J, et al. Quality criteria were proposed for measurement properties of health status questionnaires. J Clin Epidemiol. 2007;60(1):34-42. doi:10.1016/ j.jclinepi.2006.03.012.

34. R Development Core Team. R: A language and environment for statistical computing. R Foundation for Statistical Computing, Vienna, Austria. 2014. http://www.R-project.org. Accessed 28.05.2015.

35. van der Windt D, Hay E, Jellema P, Main C. Psychosocial interventions for low back pain in primary care: lessons learned from recent trials. Spine (Phila Pa 1976). 2008;33(1):81-9. doi:10.1097/BRS.0b013e31815e39f9.

36. Morso L, Albert H, Kent P, Manniche C, Hill J. Translation and discriminative validation of the STarT Back Screening Tool into Danish. Eur Spine J. 2011;20(12):2166-73. doi:10.1007/s00586-011-1911-6.

37. Morso L, Kent P, Albert HB, Hill JC, Kongsted A, Manniche C. The predictive and external validity of the STarT Back Tool in Danish primary care. Eur Spine J. 2013. doi:10.1007/s00586-013-2690-z.

38. Bruyere O, Demoulin M, Beaudart C, Hill JC, Maquet D, Genevay S, et al. Validity and reliability of the French version of the STarT Back screening tool for patients with low back pain. Spine (Phila Pa 1976). 2014;39(2):E123-8. doi:10.1097/brs.0000000000000062.

39. Gusi N, del Pozo-Cruz B, Olivares PR, Hernandez-Mocholi M, Hill JC. The Spanish version of the "STarT Back Screening Tool" (SBST) in different subgroups. Aten Primaria. 2011;43(7):356-61. doi:10.1016/j.aprim.2010.05.019.

40. Azimi P, Shahzadi S, Azhari S, Montazeri A. A validation study of the Iranian version of STarT Back Screening Tool (SBST) in lumbar central canal stenosis patients. J Orthop Sci. 2014;19(2):213-7. doi:10.1007/s00776-013-0506-y.

41. Luan S, Min Y, Li G, Lin C, Li X, Wu S, et al. Cross-cultural adaptation, reliability, and validity of the Chinese version of the STarT Back Screening Tool in patients with low back pain. Spine (Phila Pa 1976). 2014;39(16):E974-9. doi:10.1097/brs.0000000000000413.

42. Beneciuk JM, Fritz JM, George SZ. The STarT Back Screening Tool for prediction of 6-month clinical outcomes: relevance of change patterns in outpatient physical therapy settings. J Orthop Sports Phys Ther. 2014;44(9):656-64. doi:10.2519/jospt.2014.5178.

43. Klaber Moffett JA, Carr J, Howarth E. High fear-avoiders of physical activity benefit from an exercise program for patients with back pain. Spine (Phila Pa 1976). 2004:29(11):1167-72. discussion 73.

44. Smeets RJ, Vlaeyen JW, Hidding A, Kester AD, van der Heijden GJ, van Geel $A C$, et al. Active rehabilitation for chronic low back pain: cognitivebehavioral, physical, or both? First direct post-treatment results from a randomized controlled trial [ISRCTN22714229]. BMC Musculoskelet Disord. 2006;7:5. doi:10.1186/1471-2474-7-5.

45. Sanders T, Foster NE, Bishop A, Ong BN. Biopsychosocial care and the physiotherapy encounter: physiotherapists' accounts of back pain consultations. BMC Musculoskelet Disord. 2013;14(1):65. doi:10.1186/1471-2474-14-65.

46. Fritz JM, Beneciuk JM, George SZ. Relationship between categorization with the STarT Back Screening Tool and prognosis for people receiving physical therapy for low back pain. Phys Ther. 2011;91(5):722-32. doi:10.2522/ptj.20100109.

47. Jonkisz $E$, Moosbrugger $H$, Brandt $H$. Planung und Entwicklung von Tests und Fragebogen. In: Moosbrugger $\mathrm{H}$, editor. Testtheorie und Fragebogenkonstruktion. Berlin, Heidelberg: Springer; 2008. p. 27-74.

\section{Submit your next manuscript to BioMed Central and take full advantage of:}

- Convenient online submission

- Thorough peer review

- No space constraints or color figure charges

- Immediate publication on acceptance

- Inclusion in PubMed, CAS, Scopus and Google Scholar

- Research which is freely available for redistribution 